\title{
Uniaxial Loading Deformation Tests in Studying Serration Flow of Alloy C460
}

\author{
Aezeden Mohamed \\ Faculty of Engineering, University Manitoba, Winnipeg, Canada, R3T 5V6
}

\begin{abstract}
The serration flow behavior of as received and heat treated aluminum-copper-lithium alloy C460 was studied at constant strain rate and at room temperature. The observed serrated flow was similar to that observed in heat treated alloy. A very characteristic feature of deformation in this alloy was the presence of precipitates and micro slips. The suggested mechanism of serrated flow maybe involves the creation of micro slips formed by shearing of the $\mathrm{Al}_{2} \mathrm{CuLi}$ precipitates which results in restraining of dislocations.
\end{abstract}

Keywords: - C460, mircoslip, precipitates, serration, uniaxial loading

\section{INTRODUCTION}

The appearance of serration flow under uniaxial loading has been presented as the outcome of interaction between dislocations and precipitates $[1,2]$. It has also been reported that the appearance of serration flow is due to the effect of deformation slip bands [3, 4]. Another study on an Al-Mg alloy found that dislocation density may also influence serration behavior when specific microstructures develop during a uniaxial tensile test [4].

Contradictions are, therefore, found among researchers concerning the reason (s) for the serration flow effect. However, it is most commonly argued that the plastic instability or the serration is due to an interaction between dislocations and precipitates [5-8].

Serration flow behavior can be classified into three types as illustrated in the load-displacement curves in Figure 1. In Type A, the serration occurs at high strain rates with continuously propagating microslip associated with small drops in load. In Type B, the serration flow occurs at medium strain rates with smaller load drops but more frequent propagation of the microslip is observed. Finally, in Type $\mathrm{C}$, the serration flow occurs at lower strain rates and randomly nucleated microslip are observed and associated with large drops in load [9-11].

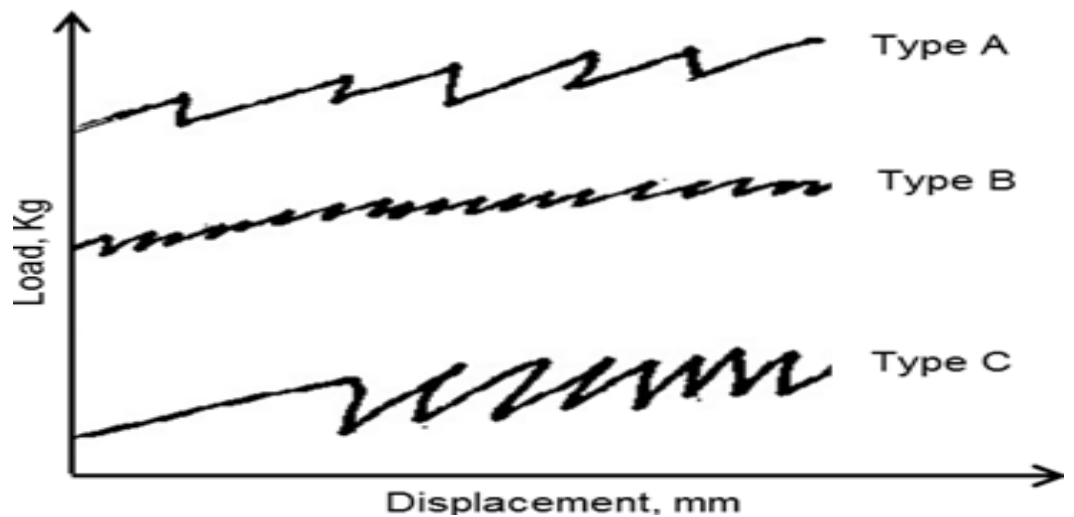

Figure 1 Scheme showing three types of serration flows.

The common observation is that serration flows are a discontinuous flow behavior during plastic deformation, with each serration flow initiated at a critical strain and with a lowering of ductility in the serrated flow $[1,12]$. Serration flow is commonly observed in FCC metals such as those formed by substitution with pure aluminum, copper, magnesium and lithium. These alloys are characterized by good ductility. However, occurrence of serration flow will reduce ductility. Aluminum-lithium alloys are available with already low ductility and fracture toughness; serration flow in these alloys will further lower ductility and fracture toughness. Serration flow also occurs in BCC metals and their alloys in which the structure is formed by interstitially dissolved elements with the result that the alloys seem mostly devoid of any regular features.

The objective of the work described in this paper was to study the causes of plastic instability and serration flow resulting from uniaxial tensile loading of $\mathrm{Al}-\mathrm{Cu}-\mathrm{Li}$ alloy $\mathrm{C} 460$ in an as received and heat treated 
condition at various aging times and at constant strain rate, and to relate serrated flow with the interaction between dislocations and precipitates.

\section{EXPERIMENTAL METHOD}

A new grade of aluminum-lithium alloy, C460, was selected for this study. The chemical composition (wt. \%) of this alloy is given as $3 \% \mathrm{Cu}, 2 \% \mathrm{Li}, .8 \% \mathrm{Zn}, .3 \% \mathrm{Mg}, .3 \% \mathrm{Mn}, .1 \% \mathrm{Zr}, .02 \% \mathrm{Fe}, .02 \% \mathrm{Si}$, Bal. $\% \mathrm{Al}$. The alloy was provided by Alcoa Aerospace and machined into cylindrical tensile specimens along the rolling direction as shown in Figure 2 (a) and Figure 3. Tensile specimens after fracture are shown in Figure 2 (b).
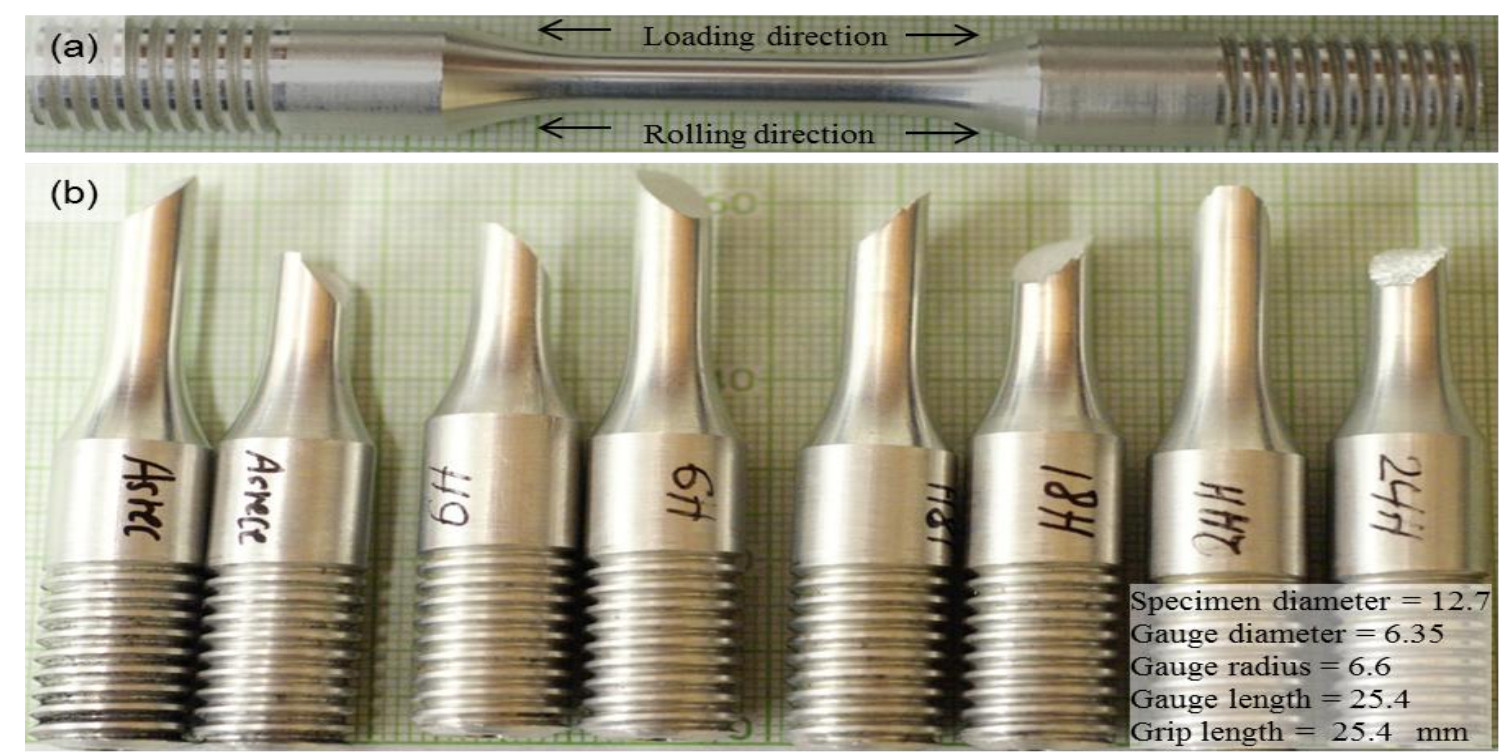

Figure 2 Cylindrical tensile test specimen (a) prior to tensile test, (b) representative tensile fracture specimens of as received and heat treated specimens aged for $6 \mathrm{hrs}, 18 \mathrm{hrs}$, and $24 \mathrm{hrs}$.

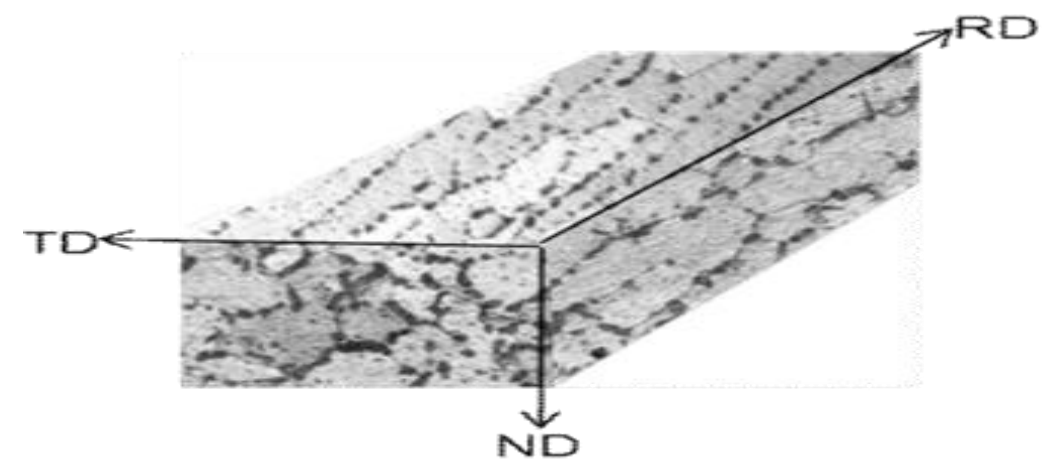

Figure 3 3D optical micrograph from gauge area indicating cross, transverse and rolling direction of grain morphology.

The tensile test specimens were solution heat treated as received for three different aging times of 6 , 18 , and 24 hours at a temperature of $160^{\circ} \mathrm{C}$. Tensile tests were carried out with a crosshead speed of $1 \mathrm{~mm} / \mathrm{min}$ on specimens of $25.4 \mathrm{~mm}$ gauge length, $6.35 \mathrm{~mm}$ gauge diameter and $6.6 \mathrm{~mm}$ gauge radius. Axial load versus axial displacement values were collected via a chart recorder. Scanning electron and transmission electron microscopes SEM and TEM were used to investigate fracture surface morphology and microstructural characterization of the various processes during uniaxial deformation, the influence of heat treatment, and the effects on uniaxial tensile properties.

\section{RESULTS AND DISCUSSIONS}

C460 alloy heat treated and aged for 6 hours before testing exhibited serrated flow behavior. No serrations appeared between the yield point to the ultimate point but were initiated between the ultimate point to fracture. This behaviour indicated that the dislocation movement was a fairly continuous process. Also, it was determined that as yielding increased with aging time, the appearance of serration flows reduced. The type of serration observed on these specimens is representative of Type B (Figure 1). 
The mechanism for the appearance of serrated flow may be explained as follows. From Figure 2 , it can be clearly seen by the naked eye that the fracture surfaces of the four specimens of C460 alloy with different heat treatments has a brittle-like appearance and are oriented at approximately $45^{\circ}$ to the loading direction (Figure 2 (b)). It should be recalled that the direction of loading was parallel to the rolling direction as indicated by the direction of elongated grains (Figure 3 ).

The serrated flow observed in the as received alloy is similar to that observed in the alloy heat treated for 6 hours. In addition, it was observed that as the aging time increased from 6 to 18 to 24 hours, the serration flow bands reduced as shown in Figure 4.

As noted earlier, it was found that the serrated flow was initiated at the ultimate tensile loading point and continued to the fracture loading point. However, the serrated flow behavior was more pronounced for specimens heat treated for 6 hours specimens than for 12 hours as shown in Figure 4 (a) and Figure 4 (b) respectively. Evidence of serration flow continued to decrease with higher aging times of 18 hours and 24 hours (Figure 4 (c) and Figure 4 (d)).

The first paragraph under each heading or subheading should be flush left, and subsequent paragraphs should have a five-space indentation. A colon is inserted before an equation is presented, but there is no punctuation following the equation. All equations are numbered and referred to in the text solely by a number enclosed in a round bracket (i.e., (3) reads as "equation 3"). Ensure that any miscellaneous numbering system you use in your paper cannot be confused with a reference [4] or an equation (3) designation.

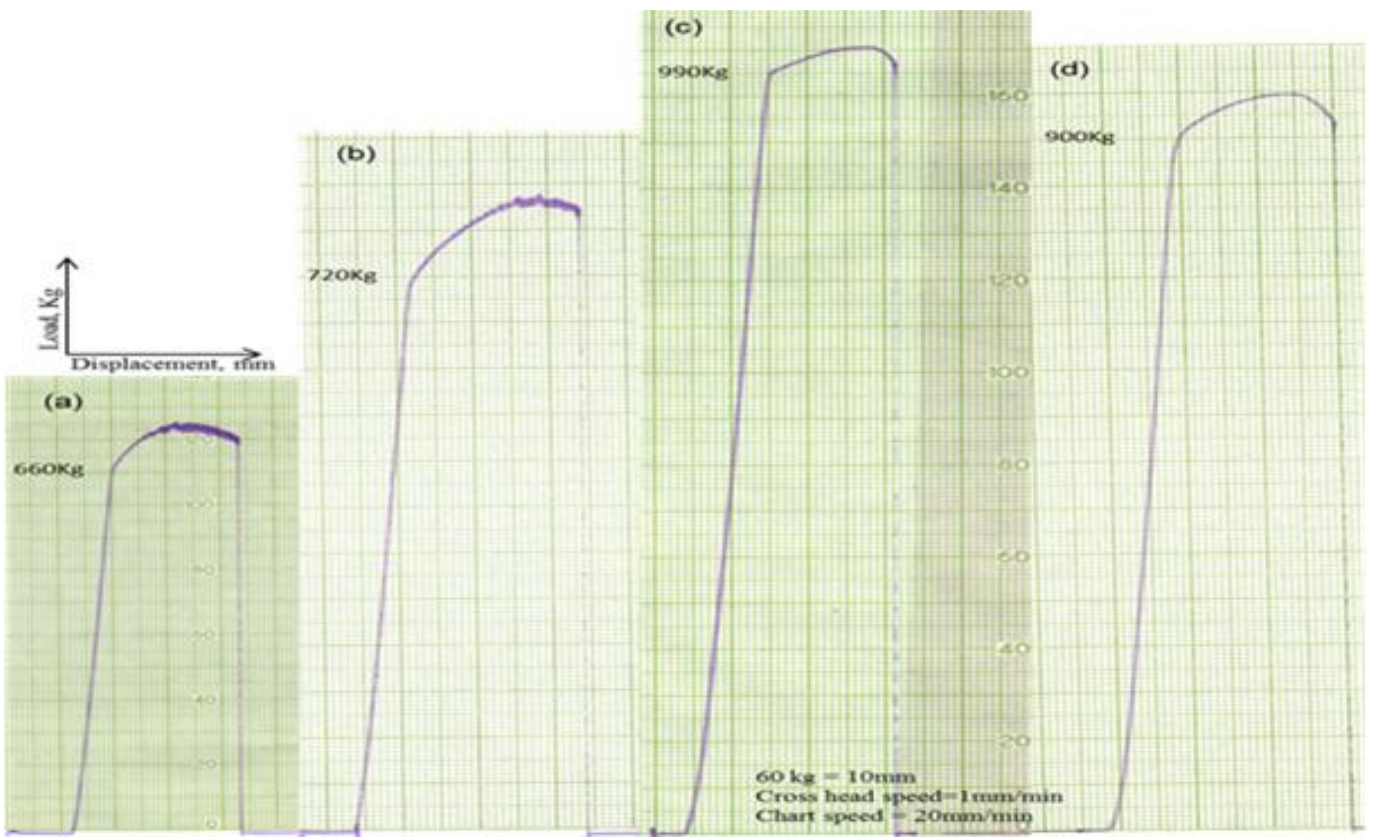

Figure 4 Load-displacement plot of C460 alloy (a) as received showing serration, (b) aged for $6 \mathrm{hrs}$ at $160^{\circ} \mathrm{C}$, (c) aged for $18 \mathrm{hrs}$ at $160^{\circ} \mathrm{C}$, (d) aged for $24 \mathrm{hrs}$ at $160^{\circ} \mathrm{C}$. Note that the serration flow decreases with increasing aging time respectively.

Yield strength and ultimate tensile strength were also influenced by aging times. For as received material, the yield strength and ultimate tensile strength are $660 \mathrm{~kg}$ and $705 \mathrm{~kg}$ respectively (Figure 4 (a)). The yield strength and ultimate tensile strength increased to $720 \mathrm{~kg}$ and $810 \mathrm{~kg}$, respectively, after 6 hours of again (Figure 4 (b)), to $990 \mathrm{~kg}$ and $1020 \mathrm{~kg}$, respectively, after 18 hours (Figure 4 (c)), but then declined to $900 \mathrm{~kg}$ and $960 \mathrm{~kg}$, respectively, after 24 hours of aging (Figure 4 (d)). As can be seen from Figure 4 selected heat treatments improved the strength of this alloy. However, the ductility and fracture toughness were unchanged, properties that are of foremost importance to materials engineers.

The specimens, after testing, were elongated up to a maximum displacement of approximately $30 \mathrm{~mm}$ (Figure 4). In Figure 4 (c) the displacement reached only $26 \mathrm{~mm}$, but there the yield and ultimate tensile strengths of 990 and $1020 \mathrm{~kg}$, respectively, are higher compared to the other aging conditions (Figure 4 (a) and Figure 4 (b)).

Fracture surface morphology in the serrated flow as observed by SEM is present as well-developed and distributed slip lines (Figure 5). These lines are essentially straight and parallel during the initial stages of deformation. With increasing strain hardening of the specimen, the step-like slip pattern likely results from the intersection of activated secondary slip lines. 

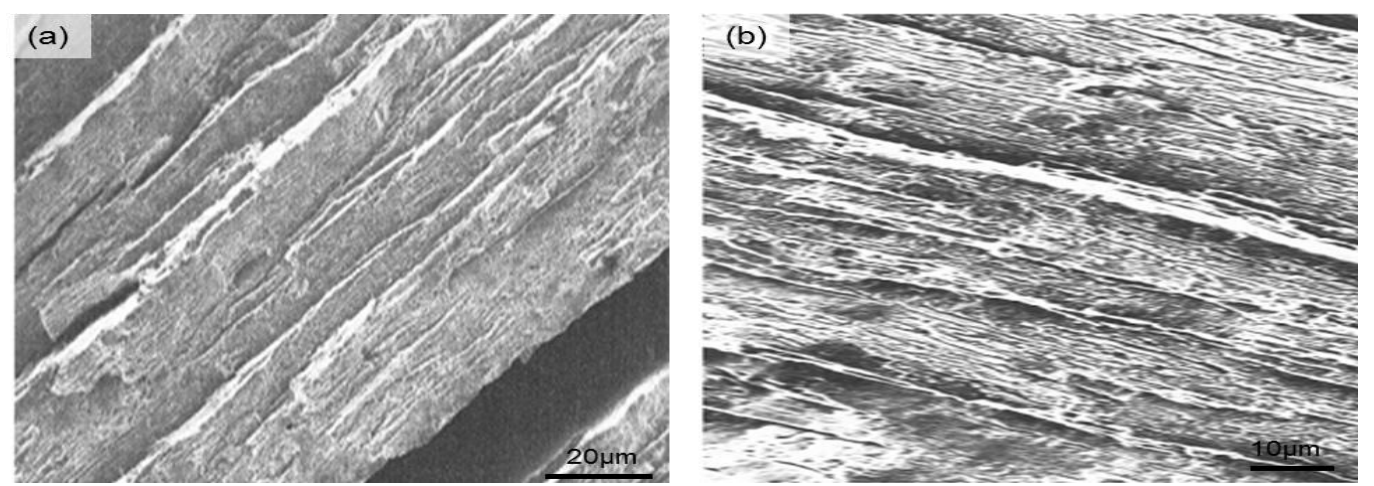

Figure 5 SEM micrographs of fracture surface of alloy C460, (a) cleavage fracture and step deformation bands, (b) deformation slip bands.

It was found that the common precipitate in $\mathrm{Al}-\mathrm{Cu}-\mathrm{Li}$ alloy $\mathrm{C} 460$ is $\mathrm{Al}_{2} \mathrm{CuLi}$ as found in the precipitation hardened specimens observed by TEM (Figure 6). This precipitate hinders dislocation motion and hence enhances plastic instability and serration flow.

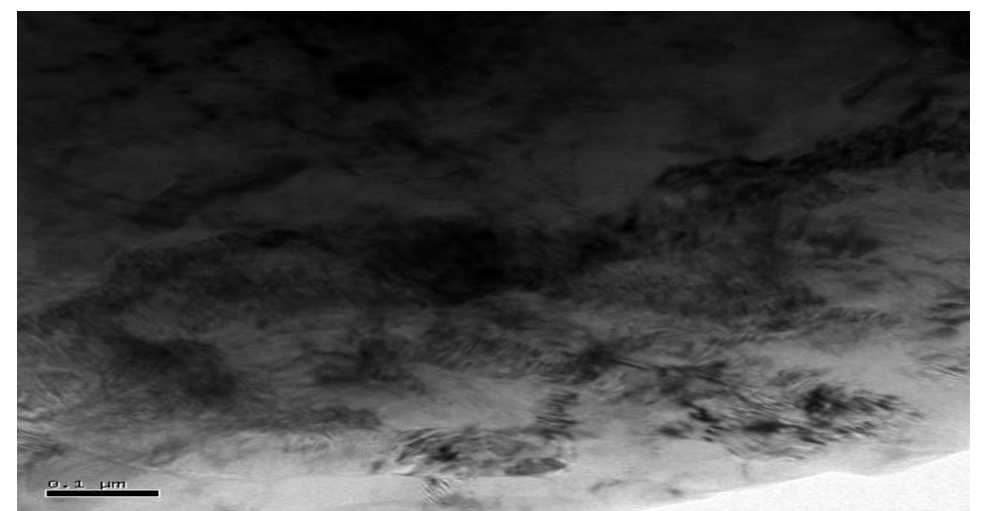

Figure 6. TEM micrograph showing $\mathrm{Al}_{2} \mathrm{CuLi}$ precipitates sheared by microslips.

In addition, diffraction contrast experiments revealed the presence of a fine distribution of $\mathrm{Al}_{2} \mathrm{CuLi}$ precipitate within the micro slips as well as in the matrix (Figure 6). In general, the dislocation arrangement was planar; the presence of dislocation pairs was also noted. Similar dislocation arrangements and patterns were also seen in the serrated flow of this alloy.

Figure 7 shows a TEM micrograph of a deformed sample of Al-Cu-Li alloy that reveals the presence of a planar array of single dislocations and microslips that appear to be aligned along crystallographic slip planes. The microslips are essentially plate-like channels within which intense dislocation activity results from the localized flow. The dislocation density within the bands appears to vary, as areas or islands of high dislocation densities and almost dislocation free were observed (Figure 7).

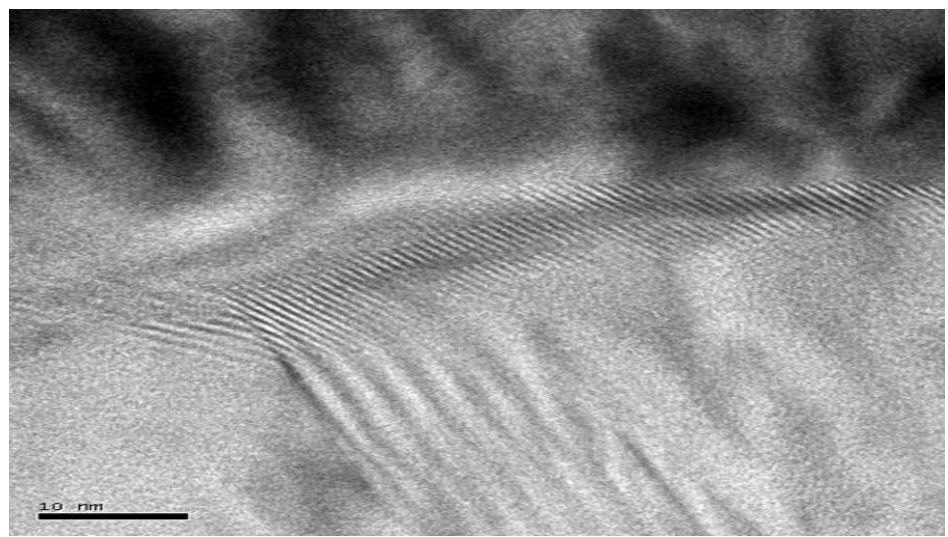

Figure 7 TEM micrograph showing micro slips of dislocations at grain boundaries in Al-Cu-Li alloy during deformation in the serrated flow behavior. 
Thus, it appears that the mechanism of plastic instability in the $\mathrm{Al}_{2} \mathrm{CuLi}$ precipitates is certainly different from the simple picture of pinning of individual dislocations and their mobilization. It is known that simultaneous activation of large number of dislocations is required to cause a plastic instability during serrated flow. TEM observation of deformed samples indicates a very inhomogeneous deformation mechanism where dislocations are restricted within the microslips or dislocation free channels. This localization of slip is promoted by the shearing of $\mathrm{Al}_{2} \mathrm{CuLi}$ precipitates and their mechanical dissolution. The mechanism of formation of the initiation of serration can be considered to involve the following steps [12, 13]. The dislocation movement is discontinuous.

Nucleation of microslips corresponds to the creation of dislocations by shearing of $\mathrm{Al}_{2} \mathrm{CuLi}$ precipitates (Figure 2) and subsequent arranging of these microslips to form deformation bands (Figure 7). Frequently, these dislocations meet $\mathrm{Al}_{2} \mathrm{CuLi}$ precipitates and are delayed for a period of time. During this time the $\mathrm{Al}_{2} \mathrm{CuLi}$ precipitates diffuse around the dislocations with further strengthening of the precipitates held at the dislocations. Eventually, these dislocations overcome the precipitates as the applied load increases and then freely go to the next region of precipitates where they are stopped again. The process repeats itself again and again.

\section{CONCLUSION}

The plastic instability associated with serrated flow behavior in alloy $\mathrm{C} 460$ was found to result from the interaction of $\mathrm{Al}_{2} \mathrm{CuLi}$ precipitates with dislocations in a form of stop-go process appear at the ultimate tensile deformation. The scale of the serration flow decreases with increasing aging time, which made dislocations move freely.

\section{REFERENCES}

[1]. Z. G. Wang, W. Liu, Y. B. Xu, T. Y. Zhang and Y. Zhang. Mechanical behavior of monocrystalline aluminum-lithium alloy at low temperatures. Scripta Metallurgica, 31(11), 1994, 1513-1518.

[2]. T. Evans. Interaction between lithium atoms and dislocations in Al-Li solid solutions. Scripta Metallurgica, 21 (11), 1987, 1435-1438.

[3]. A. Korbel, J. D. Emburg, M. Hatherly, P. L. Martin. Microstructural aspects of strain localization in Al-Mg alloys. Acta Metallurgica, 34(10), 1986, 1999-2009.

[4]. A. Korbel and P. Martin. Microscopic versus macroscopic aspect of shear bands deformation. Acta Metallurgica, 34(10), 1986, 1905-1909.

[5]. R. E. Sanders. Formability of metallic materials. (AD, STP 753, pp. 35-36, Philadelphia, PA, ASTM, 1982)

[6]. O. Engler, J. Mizera, M. Delecroix, J. Driver, and K. Lucke. In Proceedings, Conference AluminumLithium Alloys 6th, M. Peters and P.-J. Winkler, Eds., DGM, Oberursel, Germany, I, 1992, 307-3014.

[7]. S. Banerjee, U. Naik, and J. K. Chakravartty. Microscopic and macroscopic instabilities in omega forming systems. Engineering Material, 103, 1995, 267-276.

[8]. A. H. Cottrell. Effect of solute atoms on the behavior of dislocations. Proceedings, Conference on Strength of Solids, Bristol, 1947, 30-38.

[9]. J. Lépinoux, and L.P. Kubin. The dynamic organization of dislocation structures: A simulation. Scripta Materialia, 21(6), 1987, 833-838.

[10]. E. Rizzi, P. Hahner. On the Portevin-Le Chatelier effect: theoretical modeling and numerical results, International Journal of Plasticity, 20(1), 2004, 121-165.

[11]. L. Kubin, C. Fressengeas. G. Ananthakrishna. Dislocations in Solids, Duesbery, Elsevier Science, Amsterdam, 11, Ed. F. R. N. Nabarro, M. S. 2002, 101-104.

[12]. S. L. Wadekar and J. K. Chakravartty and S. Banerjee, Plastic instability in omega forming alloy systems. International Conference on Statistical Mechanics of Plasticity and Related Instabilities Indian Institute of Science, Bangalore, 2005.

[13]. J. Mizera, K. J. Kurzydlowski. On the anisotropy of the Portevin-Le Chatelier plastic instabilities in Al-Li-Cu-Zr alloy, Scripta Materialia, 45(7), 2001, 801-806. 